\title{
Avaliação da precipitação da fase sigma na soldagem de aços inoxidáveis duplex
}

\section{Evaluation of the sigma phase precipitation at the duplex stainless steel welding}

Bruno Henrique Dias Guimarães ${ }^{1}$, Carlos Roberto Xavier², Célio de Jesus Marcelo ${ }^{1}$, José Adilson de Castro ${ }^{1}$, Marcos Flávio de Campos ${ }^{1}$

\section{RESUMO}

Os aços inoxidáveis duplex (AIDs) são ligas Fe-Cr-Ni-Mo com excelentes propriedades mecânicas e de resistência à corrosão. Estas características os tornam bastantes atrativos para serem utilizados, entre outras, pelas indústrias química, petroquímica, de papel, alimentícia e farmacêutica. Entretanto, durante o processo de soldagem desses aços é muito importante se evitar a presença de fases frágeis, notadamente da fase sigma, a qual pode reduzir drasticamente suas atrativas propriedades como a resistência ao impacto e a resistência à corrosão. Este trabalho teve como objetivo avaliar a influência do aporte de calor de soldagem sobre a precipitação da fase sigma em aços inoxidáveis duplex, sendo utilizado para este fim o AID SAF 2205 e adotando o procedimento de se depositar um cordão de solda, através do processo Gas Metal Arc Welding (GMAW), sobre chapas de diferentes espessuras deste material. Análise metalográfica foi realizada na zona afetada pelo calor (ZAC) do aço investigado utilizando microscopia eletrônica de varredura (MEV) e difração de raios- $X$, não sendo constatada a presença de fase sigma para os dois níveis de aportes de calor e espessuras de chapas avaliadas neste trabalho.

Palavras-chave: Aço inoxidável duplex; Fase sigma; Soldagem; MEV; Raios-X.

\begin{abstract}
Duplex stainless steels (DSSs) are Fe-Cr-Ni-Mo alloys, which possesses excellent mechanical properties and corrosion resistance. These features make them much attractive materials for application in the chemical, petrochemical, cellulose, food and pharmaceutical industries. However, is very important to avoid the occurrence of brittle phases during the DSS welding, notably of the sigma phase, since it can drastically reduce their attractive properties as the toughness and the corrosion resistance. This work aimed to evaluate the effects of heat input on the sigma phase precipitation in DSSs, being used for this purpose the SAF 2205 DSS and adopting the bead-on-plate welding on different thickness of this material by the Gas Metal Arc Welding (GMAW) process. Scanning electronic microscopy (SEM) and X-ray diffraction were utilized for microstructural characterization of the welded samples and no evidence of sigma phase was noticed at the heat affected zone (HAZ) of the 2205 DSS using two heat input levels and the different base metal thickness evaluated in this study.
\end{abstract}

Keywords: Duplex satinless steels; Sigma phase; Welding; SEM; X-ray.

${ }^{1}$ Universidade Federal Fluminense (UFF) - Volta Redonda (RJ), Brasil.

${ }^{2}$ Centro Universitário de Volta Redonda (UniFOA)/ PETROBRAS - Volta Redonda (RJ), Brasil.

Endereço para correspondência: Bruno Henrique Dias Guimarães - Rua D, n 380, casa 02, Parque das Ilhas - CEP: 27211-035 - Volta Redonda (RJ), Brasil. E-mail: brunohdguimaraes@gmail.com

Recebido em: 31/01/2011 Aprovado em: 24/10/2014 


\section{INTRODUÇÃO}

Os aços inoxidáveis duplex (AID) são materiais baseados no sistema Fe-Cr-Ni. Sua composição química e o processamento termomecânico conferem-lhes uma microestrutura bifásica com proporções aproximadamente iguais de ferrita e austenita ${ }^{(1)}$. Tipicamente, contém cerca de 20 a 30\% de cromo, 5,0 a $10 \%$ de níquel e 1,5 a 5,0\% de molibdênio, com teores muito baixos de carbono (geralmente menores que $0,03 \%$ ) e podem ter adições de nitrogênio, cobre e tungstênio ${ }^{(2)}$. Eles apresentam várias vantagens sobre os aços inoxidáveis austeníticos e ferríticos. A resistência mecânica é aproximadamente o dobro daquela dos aços austeníticos aliada, ainda, a uma boa tenacidade.

Grande parte das aplicações atuais dos AIDs envolve algum processo de soldagem e, caso não sejam tomados os devidos cuidados, as vantagens dos AIDs sobre os aços inoxidáveis convencionais podem ser perdidas.

Durante a soldagem dos AIDs, além de procurar garantir o balanço final entre as fases ferrita e austenita, é igualmente importante se evitar a presença de fases frágeis, notadamente da fase sigma, devido à sua influência nas propriedades mecânicas e de resistência à corrosão. Ela apresenta estrutura tetragonal, sendo basicamente composta por $\mathrm{Fe}, \mathrm{Cr}$ e Mo. Esta fase é ainda caracterizada por elevados níveis de dureza (900 a $1000 \mathrm{HV}$ ) e fragilidade à temperatura ambiente ${ }^{(3)}$.

Os aportes de calor utilizados na soldagem dos AIDs devem ser altos o suficiente para promover a formação de austenita e baixas o suficiente para se prevenir a precipitação de fases deletérias ${ }^{(4)}$. Na prática, um tempo de resfriamento entre $4 \mathrm{~s}$ e $15 \mathrm{~s}$ na faixa entre $1.200^{\circ} \mathrm{C}$ e $800^{\circ} \mathrm{C}\left(\Delta \mathrm{t}_{12-8}\right)$ têm sido recomendados. Este tempo de resfriamento é normalmente obtido, dependendo da espessura do metal de base e geometria da junta, com aporte de calor entre 0,5 e 2,0 kJ/ $/ \mathrm{mm}^{(5)}$.

$\mathrm{O}$ presente trabalho teve como objetivo avaliar a influência do aporte de calor na precipitação da fase sigma durante a soldagem do aço inoxidável duplex SAF 2205.

\section{MATERIAIS E MÉTODOS}

O material para estudo foi obtido a partir de chapas laminadas de aço inoxidável duplex SAF 2205 com a composição química dada pela Tabela 1 .

As soldagens foram realizadas através do processo GMAW em simples deposição sobre amostras de aço inoxidável duplex SAF 2205 apresentando espessuras de 10 e $20 \mathrm{~mm}$, com largura e comprimento de 60 e $220 \mathrm{~mm}$ respectivamente. Como metal de adição foi empregado o consumível OK Outrod 2209 da ESAB, cuja composição química pode ser encontrada na Tabela 2 , enquanto que a composição do gás de proteção utilizado no processo GMAW está disponível na
Tabela 3. Uma vazão de 15 1/min. do gás de proteção foi utilizada em todos os experimentos, sendo que na Tabela 4 podem ser encontrados os aportes de calor investigados neste trabalho.

Tabela 3: Gás de proteção (processo: GMAW).

\begin{tabular}{|c|c|c|}
\hline \multicolumn{3}{|c|}{ Composição (\%)* } \\
\hline \multicolumn{3}{|c|}{$95 \% \mathrm{Ar}-3 \% \mathrm{CO}_{2}-2 \% \mathrm{~N}_{2}$} \\
\hline \multicolumn{3}{|c|}{${ }^{*}$ Composição química e aplicação patenteadas pela White Martins/Praxair } \\
\hline CP & Espessura (mm) & Aporte $(\mathrm{kJ} / \mathrm{mm})$ \\
\hline 1 & 10 & 0,66 \\
\hline 2 & 10 & 2,57 \\
\hline 3 & 20 & 0,66 \\
\hline 4 & 20 & 2,57 \\
\hline
\end{tabular}

\section{Preparação Metalográfica}

Para lixamento foram utilizadas lixas de Carbeto de Silício (SiC) com resfriamento e lubrificação em água, com granulometrias de: 220, 320, 400, 600, 800, 1000, 1200 e 1500 mesh. Em seguida foi realizado o polimento das amostras com pasta de diamante na seqüência: $6,3,1$ e 1/4 $\mu \mathrm{m}$ de tamanho médio de partícula.

Com as amostras devidamente polidas, realizou-se o ataque químico com o reagente de BERAHA. Os componentes deste reagente são: água $\left(\mathrm{H}_{2} \mathrm{O}\right)$, ácido clorídrico $(\mathrm{HCl})$ e metabissulfito de potássio $\left(\mathrm{K}_{2} \mathrm{~S}_{2} \mathrm{O}_{5}\right)$. Inicialmente, foi preparada a solução estoque, constituída de uma mistura de $1000 \mathrm{ml}$ de água com $200 \mathrm{ml}$ de ácido clorídrico. Esta solução pode ser armazenada por até dois anos, já o metabissulfito de potássio deve ser adicionado somente no momento do ataque, pois seu período de atuação na solução é bastante curto. Para cada $100 \mathrm{ml}$ de solução estoque foram adicionados $0,3 \mathrm{~g}$ de metabissulfito de potássio. As amostras foram atacadas até que suas superfícies adquirissem uma coloração azul escuro. Feito isso, as amostras foram tiradas da solução e imediatamente lavadas com álcool etílico absoluto e secas com ar quente.

\section{Raios-X}

Uma das técnicas de caracterização microestrutural adotada neste estudo para a avaliação da ZAC do aço investigado foi a difração de raios-X. Desta forma, os corpos de prova para a difração foram preparados com a mesma seqüência de lixas usadas na preparação para análise metalográfica, porém, sem polimento e ataque. O equipamento utilizado foi o difratômetro marca Shimadzu modelo XRD-6000.

\section{Microscopia Eletrônica de Varredura (MEV)}

A ZAC das amostras soldadas também foi analisada através de microscopia eletrônica de varredura (MEV). O equipamento utilizado

Tabela 1: Composição química do AID SAF 2205 (\% em peso).

\begin{tabular}{c|c|c|c|c|c|c|c|c|c|c|}
\hline $\mathbf{C}$ & $\mathbf{M n}$ & $\mathbf{P}$ & $\mathbf{S}$ & $\mathbf{S i}$ & $\mathbf{C u}$ & $\mathbf{C r}$ & $\mathbf{M o}$ & $\mathbf{N i}$ & $\mathbf{N}$ \\
\hline 0,023 & 1,85 & 0,32 & 0,001 & 0,32 & 0,03 & 22,50 & 2,90 & 5,3 & 0,166 \\
\hline
\end{tabular}

Tabela 2: Composição química do metal de adição (\% em peso).

\begin{tabular}{c|c|c|c|c|c|c|c|c|c|c|}
\hline $\mathbf{C}$ & $\mathbf{M n}$ & $\mathbf{P}$ & $\mathbf{S}$ & $\mathbf{S i}$ & $\mathbf{C u}$ & $\mathbf{C r}$ & $\mathbf{M o}$ & $\mathbf{N i}$ & $\mathbf{N}$ \\
\hline 0,01 & 1,60 & 0,01 & 0,01 & 0,60 & 0,03 & 23,00 & 3,03 & 9,00 & 0,10 \\
\hline
\end{tabular}


foi o Microscópio Eletrônico de Varredura Zeiss modelo EVO MA$10 \mathrm{~A}$ operando a uma tensão de $25 \mathrm{kV}$. Foram utilizadas imagens geradas por elétrons secundários e elétrons retroespalhados. Como o objetivo fundamental do trabalho foi a avaliação da precipitação da fase sigma, as imagens de elétrons retroespalhados foram preferencialmente utilizadas, desde que esta técnica possibilita que este precipitado se destaque na microestrutura por apresentar uma tonalidade mais clara devido ao seu maior teor de molibdênio.

\section{RESULTADOS E DISCUSSÕES}

A Fig. 1 corresponde à macrografia representativa de todas as condições de soldagem avaliadas neste estudo, abrangendo várias regiões como a zona fundida, ZAC e metal-base.

Pode ser vista na Fig. 2 a microestrutura do material como recebido. Imagens de elétrons retroespalhados não evidenciaram a presença de outros constituintes e fases além da ferrita e da austenita, a qual se apresenta na forma de grãos alongados.

Difração de raios-X foi realizada na ZAC de todas as amostras soldadas. De acordo com os resultados obtidos, não foi constatada a presença de fase sigma para os dois níveis de aporte de calor de soldagem investigados neste trabalho. Como todas as condições de soldagem investigadas apresentaram idêntico difratograma, somente um será usado como representativo a todos (Fig. 3).

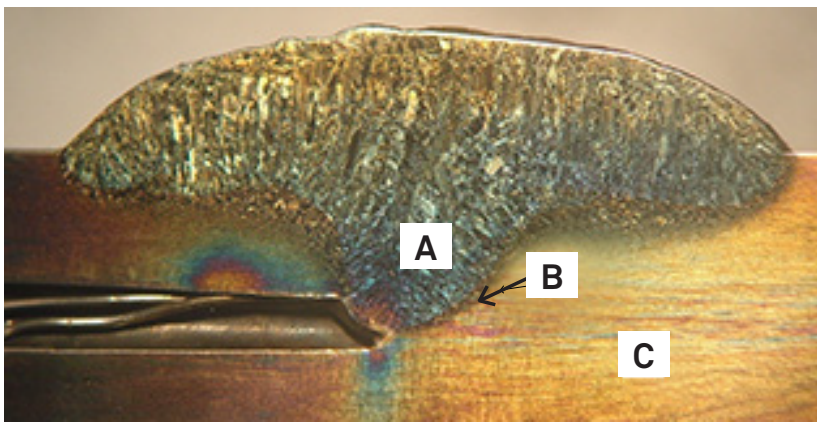

Figura 1: Macrografia exibindo Zona Fundida (A), ZAC (B) e metal-base (C).

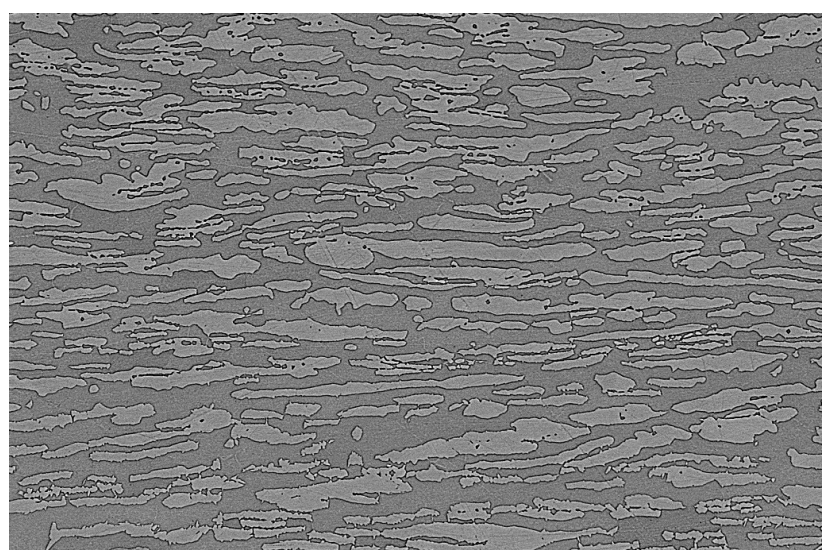

Escala 10 $4 \mathrm{~m} ; \mathrm{AA} 1070$ - ECAP; Signal A = CZ BSD; WD = 10.0mm $\mathrm{EHT}=20.00 \mathrm{kV}$; Mag $=1.00 \mathrm{KX}$

Figura 2: Microestrutura do material como recebido.

A análise por Microscopia Eletrônica de Varredura foi feita em todas as amostras soldadas, complementando as análises efetuadas por difração de raios-X. Mais uma vez não foi encontrado indício da precipitação da fase sigma em qualquer das condições de soldagem avaliadas. Nas Figs. 4 e 5, cujas imagens foram geradas através de elétrons retroespalhados, são exibidas a ZAC das amostras soldadas com maior e menor aporte de calor de soldagem considerando, ainda, as duas espessuras avaliadas, tendo sido encontrado somente a presença das fases ferrita e austenita.

\section{CONCLUSÃO}

Não foi constatada a presença de fase sigma na ZAC do aço inoxidável duplex 2205 para os dois níveis de aportes de calor de soldagem e para as duas espessuras de chapas investigadas, quando esta região da solda foi analisada utilizando como técnicas de caracterização microestrutural a difração de raios-X e MEV. Além disso, o trabalho mostrou que a utilização destas duas técnicas em conjunto (MEV e difração de raios-X) pode ser uma eficaz e importante ferramenta na caracterização microestrutural de aços inoxidáveis duplex, antes e após a sua soldagem, auxiliando na identificação, entre outros, de precipitados como a fase sigma.

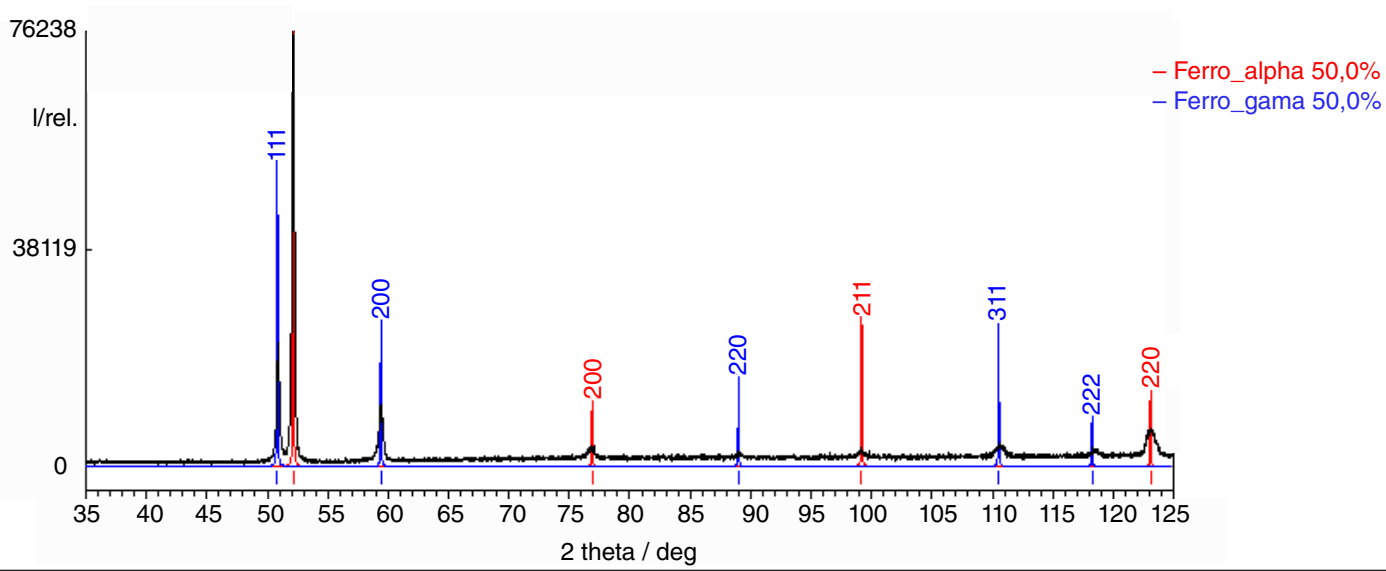

Figura 3: Difração de raios-X representativa da ZAC de todas as condições investigadas. 

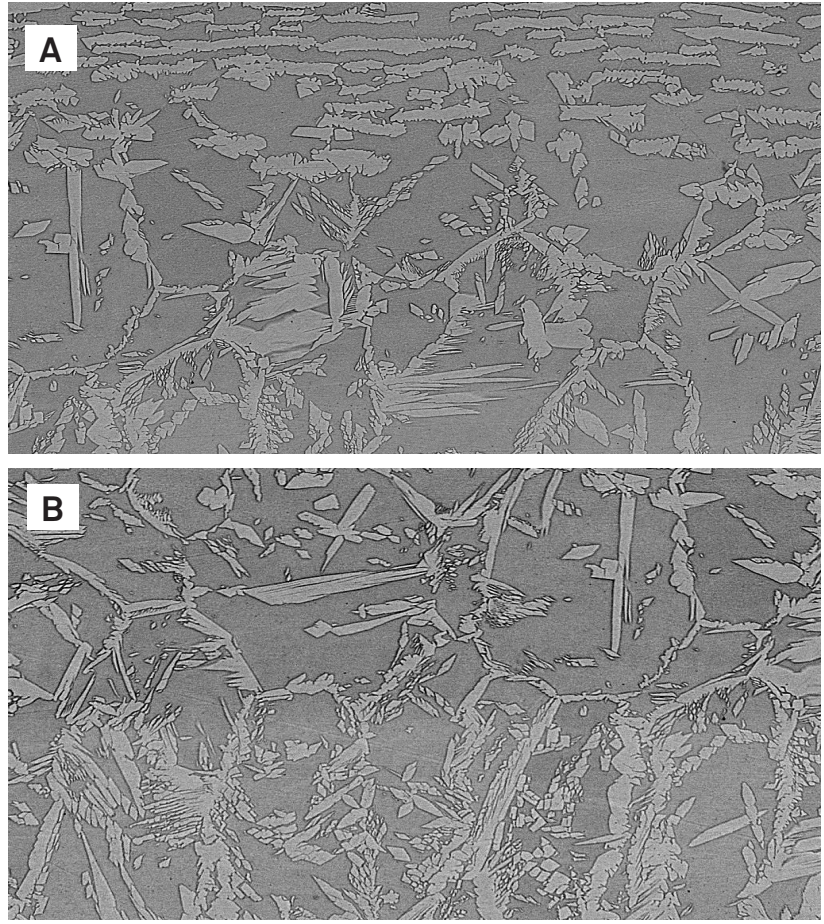

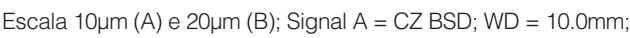
$\mathrm{EHT}=20.00 \mathrm{kV} ; \mathrm{Mag}=1.00 \mathrm{KX}$

Figura 4: Microestrutura da ZAC: (A) 0,66 kJ/mm e (B) 2,57 kJ/mm (espessura: $10 \mathrm{~mm}$ ).

\section{AGRADECIMENTOS}

Ao $\mathrm{CNPq}$ e FAPERJ. Igualmente às empresas Aperam South America, ESAB e White Martins pelo fornecimento dos recursos materiais para estudo e pela presteza em fornecer as informações necessárias sempre que requisitadas.

\section{REFERÊNCIAS}

1. RAMIREZ LONDOÑO, A.J., Estudo da precipitação de nitreto de cromo e fase sigma por simulação térmica da zona afetada pelo calor na soldagem multipasse de aços inoxidáveis duplex. Dissertação de Mestrado (1997). Escola Politécnica/USP, São Paulo (SP).
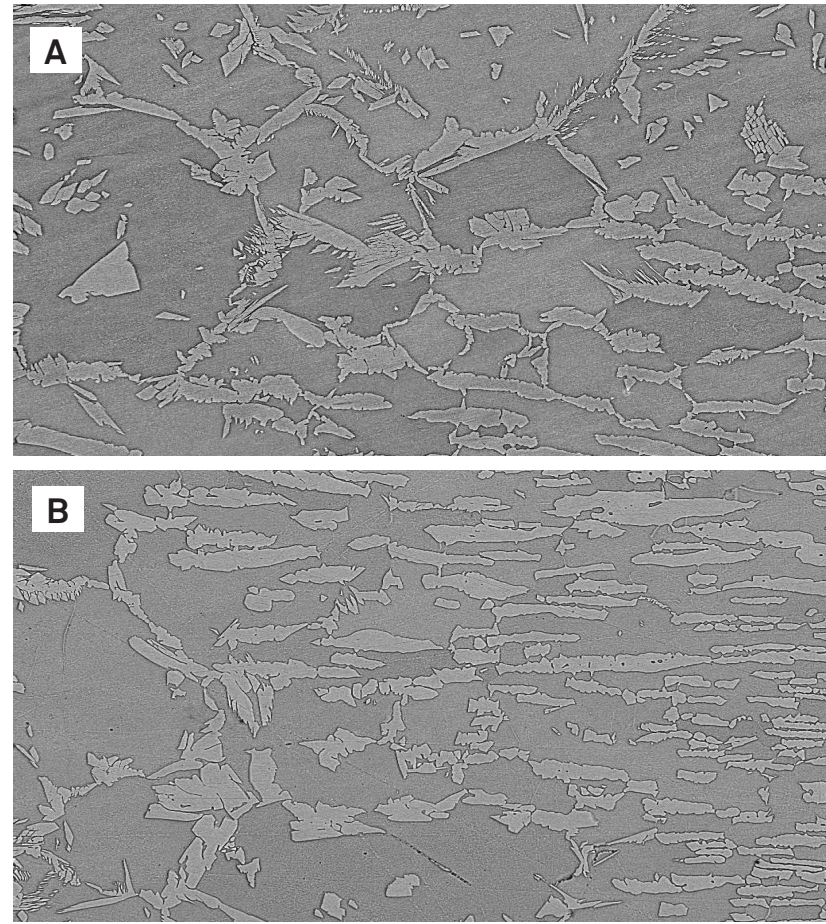

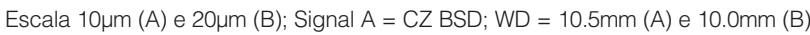
$\mathrm{EHT}=20.00 \mathrm{kV}(\mathrm{A})$ e $25.00 \mathrm{kV}(\mathrm{B}) ; \mathrm{Mag}=1.00 \mathrm{KX}$

Figura 5: Microestrutura da ZAC: (A) 0,66 kJ/mm e (B) $2,57 \mathrm{~kJ} / \mathrm{mm}$ (espessura: $20 \mathrm{~mm}$ ).

2. SOLOMON, HD.; DEVINE, T.M. "A tale of two phases", In: Conference Duplex Stainless Steels'82, St. Louis-ESA, Ohio, USA, 1983, p. 693-756.

3. MAEHARA, Y.; KOIKE, M.; FUJINO, N.; KUNITAKE, T. Precipitation of fase $\tau$ in 25Cr-7Ni-3Mo duplex phase stainless steel. Transactions ISIJ. V. 23 (1983), p. 240-246.

4. GUNN, R.N., Duplex Stainless Steels: Microstructures, Properties and Applications. Cambridge: Abington Publishing, 1997, p. 204.

5. LILJAS, M. The welding metallurgy of duplex stainless steels. In: Conference Duplex Stainless Steels'94, Glasgow-Scotland, Escócia, 1994, Proceedings: TWI, paper KV. 